\title{
The Modification of Rheological Properties of Bentonite-Water Dispersions with Cationic and Anionic Surfactants
}

\author{
Basim Abu-Jdayil, Mamdouh Ghannam, and Mustafa S. Nasser
}

\begin{abstract}
In the use of bentonite in different industrial applications, different additives are recommended to optimize the rheological properties of the formulation. In this study, the effect of anionic surfactant sodium dodecyl sulfate (SDS) and cationic surfactant cetyltrimethyl ammonium bromide (CTAB) on the rheological properties of Na-bentonite suspensions was investigated in the concentration range of $1.0 \times 10^{-3}-1.0 \times$ $10^{-1} \mathrm{M}$. The SDS surfactant was effective in modifying the rheological behavior of bentonite dispersion in the concentration range that corresponds to critical micelle concentration (CMC) and critical coagulation concentrations (CCC) of SDS. On the other hand, the addition of CTAB surfactant to bentonite suspension reduced significantly its viscosity and shifted its behavior from shear thinning with a yield stress toward Newtonian.
\end{abstract}

Index Terms-Adsorption, bentonite, CTAB, SDS, rheology, Thixotropy.

\section{INTRODUCTION}

Recently, the use of natural minerals in different industrial applications increasingly attracts attention because of their abundance and low cost. One of the important natural minerals is the bentonite, which consists mainly of montmorillonite and contains varying amounts of other minerals like quartz and feldspar. The structure and swelling properties of $\mathrm{Na}$-bentonite provide it with exceptional rheological properties that allow its dispersions to be widely used in different industrial applications, such as in drilling muds [1], [2], dyes, pharmaceuticals [3], paper, cement [4], nanocomposites [5], [6], polymer composites [7], thermal insulators [8] and ceramics [9].

In addition to the pervious applications, and due to the fact that bentonite is a porous solid that is capable of adsorption both physical and chemical, it was used widely as a sorbent for different pollutants such as heavy metals [10] and organic pollutants [11]. However, the efficiency of bentonite as a sorbent was modified by using organic surfactants to change the surface of the clay from hydrophilic to hydrophobic [12], [13]. Then the pollutants are adsorbed on the hydrophobic clay surface, where the solutes are captured by hydrophobic interaction between alkyl chains [14]. The cationic surfactant cetyltrimethyl ammonium bromide (CTAB) [13], [15], [16] and the anionic surfactant sodium dodecyl sulphate (SDS)

Manuscript received April 1, 2015; revised June 20, 2015.

B. Abu-Jdayil and M. Ghannam are with the Chemical and Petroleum Engineering Department, UAE University, Al Ain, UAE (e-mail: babujdayil@uaeu.ac.ae; mamdouh.ghannam@uaeu.ac.ae).

M. S. Nasser is with the Gas Processing Center, Qatar University, Doha, Qatar (e-mail: m.nasser@qu.edu.qa).
[17]-[19] were used widely to improve the sorption properties of bentonite.

On the other hand, the addition of surfactants to bentonite dispersions can induce flocculation of fine particles by bridging, charge neutralization, surfactant-particle surface complex formation and depletion flocculation, or by a combination of these mechanisms. The bridging mechanism requires that the surfactant chains be adsorbed on the particle surfaces, with only a few points of attachment, with the bulk of the chains projecting into the surrounding solution for contact and adherence to other particles. Strong adsorption does not favor the flocculation process, because strong adsorption can cause surface saturation, preventing effective bridging and destabilizing fine particles. Intercalation also occurs as a competing mechanism [20].

Although the effects of surfactants on the rheology of bentonite dispersions have received good attention in the literature, few studies have reported the effect of SDS and CTAB [2]-[23]. Most of these studies were conducted on low clay concentration. In addition, the thixotropic behavior of bentonite dispersion, which is an important property for different applications, did not receive enough attention. Thus, the aim of this work is to compare between the effects of addition of the cationic surfactant $\mathrm{CTAB}$ and the anionic surfactant SDS on both shear dependent and time dependent rheological properties of bentonite dispersions at the same conditions.

\section{Materials AND Methods}

\section{A. Materials}

Bentonite used in this study was supplied by Sigma-Aldrich CHEMIE GmbH, Germany. The sample has the following composition (wt\%): $\mathrm{Na}_{2} \mathrm{O} 2.425 ; \mathrm{K}_{2} \mathrm{O} 0.245$; $\mathrm{Fe}_{2} \mathrm{O}_{3}$ 3.250; $\mathrm{MgO}$ 2.670; $\mathrm{Al}_{2} \mathrm{O}_{3} 21.080 ; \mathrm{SiO}_{2}$ 63.020; $\mathrm{CaO}$ $0.650 ; \mathrm{FeO} 0.350 ; \mathrm{H}_{2} \mathrm{O}$ 5.65; trace elements 0.72 . The particle size of bentonite was less than $74 \mu \mathrm{m}$ with an average of $5.34 \mu \mathrm{m}$. Sodium dodecyl sulfate (SDS) and cetyltrimethyl ammonium bromide (CTAB) used in this investigation were obtained from Sigma-Aldrich.

\section{B. Samples Preparation}

Bentonite suspensions with $8.0 \mathrm{wt} \%$ solid concentration were prepared in this study for rheological measurements. The pure bentonite dispersions were prepared by adding bentonite slowly to deionized water under magnetic stirring conditions, to avoid the formation of aggregates and ensure homogeneous dispersion. In the case of bentonite-surfactant dispersions, the surfactant solutions $\left(1.0 \times 10^{-3} \mathrm{M}\right.$, 
$2.0 \times 10^{-3} \mathrm{M}, 5.0 \times 10^{-3} \mathrm{M}, 1.0 \times 10^{-2} \mathrm{M}, 2.0 \times 10^{-2} \mathrm{M}$, $5.0 \times 10^{-2} \mathrm{M}$ and $1.0 \times 10^{-1} \mathrm{M}$ ) were prepared firstly, then the bentonite powder was added slowly to the solution while stirring. After mixing, each bentonite dispersion was poured in a covered container and left for a specific time at room temperature. The measured $\mathrm{pH}$ of the bentonite dispersions was $8.61 \mp 0.04$. The rheological properties of samples were measured at $24 \mathrm{hr}$ after preparation. Prior to rheological measurement, the sample was stirred in the viscometer for 1 min at shear rate of $5 \mathrm{~s}^{-1}$, followed by a rest time for two minutes.

\section{Rheological Measurements}

The rheological properties of prepared dispersions were measured with a Rheolab QC viscometer from Anton Paar, Germany. Coaxial cylinder with measuring system used is according to ISO 3219 and DIN 53019. The dimensions corresponding to the geometry were $14.460 \mathrm{~mm}$ for the radius of the measuring cup, $13.329 \mathrm{~mm}$ for the radius measuring bob and $120^{\circ}$ cone angle. This geometry allows a gap width of $1.132 \mathrm{~mm}$. The shear stress $(\tau)$ of the samples was measured as a function of shear rate $(\dot{\gamma})$ at a constant temperature. The rheological measurements were performed in the shear rates range from 500 up to $1500 \mathrm{~s}^{-1}$. This range of shear rate covers wide range of industrial applications. All rheological tests were performed at $25{ }^{\circ} \mathrm{C} \mp 0.1$. The measurements were carried out with increasing (forward measurements) and decreasing (backward measurements) shear rates. The area between the upward and downward curves was calculated as a measure for thixotropy using data analysis option of RHEOPLUS/32 V3.31 software. All measurements were performed in duplicate. The percentage difference in the measured shear stress was on average less than $3 \%$. The average values were reported here.

\section{Zeta Potential Measurements}

Zeta potential measurements were carried out by Zeta/nano particle analyzer (NanoPlus) from Otsuka Electronics CO LTD (Japan), to determine the effect of surfactant concentration on the electrokinetic properties of bentonite particles

\section{RESULTS AND DISCUSSION}

\section{A. Pure Bentonite}

The rheological behavior of pure bentonite was reported in details for solid concentrations of $0.5-10.0 \mathrm{wt} \%$ in previous studies [24], [25]. Fig. 1 shows the flow curve of the pure bentonite dispersions for 4.0 and $8.0 \mathrm{wt} \%$ solid concentrations. Bentonite dispersions examined in this investigation showed non-Newtonian behavior. Modeling analysis was carried out to predict the most relevant model that represents the rheogram behavior. From the investigation of this analysis, the well-known Herschel-Bulkley model was found to fit all the measured data of the bentonite suspensions:

$$
\tau=\tau_{0}+m \dot{\gamma}^{n}
$$

where $\tau$ is the shear stress, $\tau_{o}$ is the yield stress, $\dot{\gamma}$ is the shear rate, $m$ is the consistency coefficient and $n$ is the flow behavior index. The regressed parameters of Herschel-Bulkley model, which are reported in Table I, reveal that the $8 \mathrm{wt} \%$ bentonite suspension exhibited shear thinning behavior with a remarkable yield stress. It is expected that the bentonite concentration will bring about an increase of all rheological properties like the yield stress $\tau_{o}$ and the flow behavior index $(m)$. In the case of high bentonite concentration (like $8.0 \mathrm{wt} \%$ ), flocculation will cause the formation of a continuous networked structure instead of individual flocs that occur in lower concentrations. The network structure build up slowly with time, as the particles orient themselves towards positions of minimum free energy under the influence of Brownian motion [26].

TABLE IA: HERSCHEL-BULKLEY PARAMETERS OF 8 WT\% BENTONITE SUSPENSIONS AT DIFFERENT SDS CONCENTRATIONS

\begin{tabular}{|c|c|c|c|c|}
\hline \multirow{2}{*}{$\begin{array}{l}\text { Surfactant Conc. } \\
(\mathrm{wt} \%)\end{array}$} & \multicolumn{3}{|c|}{ SDS } & \multirow[b]{2}{*}{$\begin{array}{l}A \\
(\mathrm{~Pa} / \mathrm{s})\end{array}$} \\
\hline & $\begin{array}{l}\tau_{0} \\
(\boldsymbol{P a})\end{array}$ & $\begin{array}{l}m \times 10^{5} \\
\left(P a \cdot s^{n}\right)\end{array}$ & $n$ & \\
\hline 0.0 & 8.6 & 2618.9 & 0.95 & 3189 \\
\hline $1.0 \times 10^{-3}$ & 6.9 & 2333.6 & 0.98 & 1726 \\
\hline $2.0 \times 10^{-3}$ & 6.4 & 1875.0 & 1.0 & 1581 \\
\hline $5.0 \times 10^{-3}$ & 2.7 & 1690.3 & 1.0 & 1199 \\
\hline $1.0 \times 10^{-2}$ & 4.4 & 2070.0 & 1.0 & 1322 \\
\hline $2.0 \times 10^{-2}$ & 11.5 & 2149.0 & 1.0 & 3314 \\
\hline $5.0 \times 10^{-2}$ & 7.3 & 1994.0 & 1.0 & 1389 \\
\hline $1.0 \times 10^{-1}$ & 6.7 & 1660.0 & 1.0 & 1486 \\
\hline
\end{tabular}

TABLE IB: HERSCHEL-BULKLEY PARAMETERS OF 8 WT\% BENTONITE SUSPENSIONS AT DIFFERENT CTAB CONCENTRATIONS

\begin{tabular}{cllll}
\hline $\begin{array}{c}\text { Surfactant Conc. } \\
(\text { wt\% })\end{array}$ & \multicolumn{5}{c}{ CTAB } \\
\cline { 2 - 5 } & $\tau_{0} m \times 10^{5}$ & $n$ & $\begin{array}{l}A \\
(P a / s)\end{array}$ \\
& $(P a)$ & $\left(P a \cdot s^{n}\right)$ & & \\
\hline 0.0 & 8.65 & 2618.9 & 0.95 & 3189 \\
$1.0 \times 10^{-3}$ & 0.91 & 1508.0 & 1.0 & 987 \\
$2.0 \times 10^{-3}$ & 0.0 & 1400.0 & 1.0 & 497 \\
$5.0 \times 10^{-3}$ & 0.0 & 1380.0 & 1.0 & 433 \\
$1.0 \times 10^{-2}$ & 0.0 & 1220.0 & 1.0 & 394 \\
$2.0 \times 10^{-2}$ & 0.0 & 1190.0 & 1.0 & 297 \\
$5.0 \times 10^{-2}$ & 0.0 & 1010.0 & 1.0 & 120 \\
$1.0 \times 10^{-1}$ & 0.0 & 975.3 & 1.0 & 49 \\
\hline
\end{tabular}

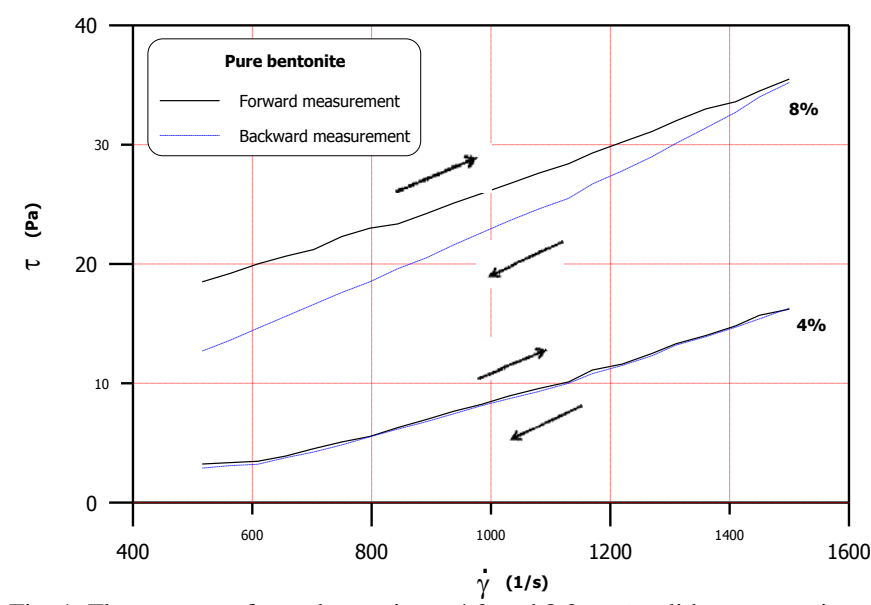

Fig. 1. Flow curves of pure bentonite at 4.0 and $8.0 \mathrm{wt} \%$ solid concentration

In order to investigate the time dependent behavior of the bentonite, the rheological tests were performed by increasing shear rate (forward measurement) followed by decreasing the shear rate (backward measurement), see Fig. 1. The presence of hysteresis loops, difference between the forward and backward measurements, reveals that the suspension showed 
a thixotropic behavior. It should be mentioned that if the viscosity reduces and immediately returns after shearing, the material is not thixotropic but just shear thinning. Fig. 1 shows that the $8.0 \mathrm{wt} \%$ bentonite dispersion exhibited a clear thixotropic behavior. The thixotropic behavior has been reported for many clay dispersions [27], [28], which was concentration dependent. The thixotropic behavior increased significantly with solid concentration [24]. This occurs because the fragments of the network which are broken under shear, need time to be restructured again to a three-dimensional network [26]. The network structure can be broken by shear stress and interparticle bonds tend to reestablished themselves with time. The presence of thixotropy means that the rate of bond breakdown is greater than the rate of rebuilding process.

\section{B. Bentonite-Surfactant-Mixture}

The flow curves of bentonite suspension in the presence of different SDS concentrations are shown in Fig. 2. Initial addition of SDS surfactant to $8.0 \mathrm{wt} \%$ bentonite dispersion resulted in a decrease in the shear stress values to reach a minimum at $5.0 \times 10^{-3} \mathrm{M}$ of SDS, then these values increased up to show a maximum at $2.0 \times 10^{-2} \mathrm{M}$ SDS concentration and again a decrease was observed at higher SDS concentration. Hoffmann et al. [29] show that the surfactant based formulations show strong dependence on the surfactant concentration. It was found that as the concentration of a soluble surfactant in water increased, the individual surfactant monomers began to aggregate, with their hydrophilic heads being accommodated by the water phase and their hydrophobic tails extending out of the water phase in order to minimize the free energy of the system. The concentration at which this aggregation occurs is called the critical micelle concentration (CMC), and the aggregates are called micelles. Micelles are, generally, spherical in shape and are about $4-10 \mathrm{~nm}$ in diameter [30]. These spherical shape micelles could reduce the bridging mechanism between the surfactant and bentonite and may also act as burier between bentonite-bentonite particles.

As total surfactant concentration is further increased, other strong and elastic micelle shapes may form, such as cylindrical, hexagonal-packed, and lamellar structures which may improve the bridging mechanism between the surfactant and bentonite and hence increase the viscosity. It should be mentioned that this range of surfactant concentration $\left(1.0 \times 10^{-2}-2.0 \times 10^{-2}\right)$ corresponds to the critical micelle concentration (CMC) of SDS in pure water, which is $0.0095 \mathrm{M}$ [31] and the critical coagulation concentration of SDS, CCC, which is the minimum salt concentration that is needed to cause coagulation of a colloidal dispersion [22]. There are three possibilities of interactions between negative charge-carrying bentonite particles and SDS anionic surfactant [22]. The first possibility is that ion exchange can take place between $\mathrm{OH}^{-}$ions on bentonite surfaces and the anionic part of surfactant $\mathrm{CH}_{3}\left(\mathrm{CH}_{2}\right)_{11} \mathrm{OSO}_{3}^{-}$. The second possibility is that $\mathrm{H}$-bonds can form between bentonite particles and surfactant molecules. Third, it is possible that $\mathrm{Ca}^{2+}$ cation can establish electrostatic bridges between the anionic part of surfactants and the surface of bentonite particles. All these possibilities for the mechanism of adsorption of anionic surfactant by bentonite surfaces can occur here. It is clear that the SDS adsorbed by bentonite particles in the concentration range of $1.0 \times 10^{-2}$ and $2.0 \times 10^{-2} \mathrm{M}$ tended to cause aggregation due to interactions between the hydrophilic tails of SDS surfactant and the positive edge of the bentonite particles, which resulted in the formation of more resistant structure against shearing process. As the concentration of SDS was increased to the higher concentrations $\left(5.0 \times 10^{-2} \mathrm{M}-1.0 \times 10^{-1} \mathrm{M}\right)$, a decrease in the apparent viscosity of bentonite suspension was observed. As the surfactant concentration increase, the adsorption of surfactant on the bentonite surface will be increased. This strong adsorption can cause surface saturation, preventing effective bridging and reestablishing the bentonite particles and causing drop in the viscosity of the suspension. Similar behavior was observed by Tunc et al. [32].

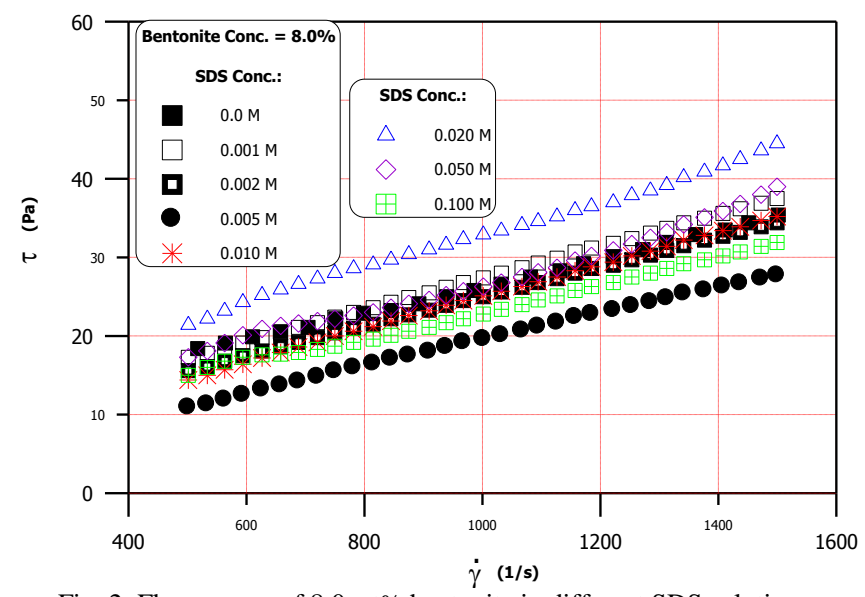

Fig. 2. Flow curves of $8.0 \mathrm{wt} \%$ bentonite in different SDS solution concentrations.

As can be seen in Fig. 3, adding the cationic surfactant $\mathrm{CTAB}$ to the bentonite dispersions led in general to decrease its shear stress values. The apparent viscosity of bentonite dispersions decreased significantly until the addition of $2.0 \times 10^{-2} \mathrm{M}$ CTAB. Beyond $2.0 \times 10^{-2} \mathrm{M}$, the influence of CTAB addition on the flow behavior of bentonite dispersions was insignificant. The reduction in bentonite suspension viscosity is owing to the decrease in the degree of flocculation. It is known that the occupation of exchange sites on the bentonite surface by cationic surfactants will change the surface properties from hydrophilic to hydrophobic [13]. This will lead to increase the bentonite suspension viscosity due to the binding of positively charged surfactant molecules onto the negatively charged bentonite particles via mainly electrostatic interactions. Moreover, the hydrophobic tail of CTAB molecules adsorb onto the bentonite particles interacts with the tail group of CTAB attached onto other particles by hydrophobic interactions to produce large flocs [12], [32]. In the current study, it is expected that this mechanism did not take place in the investigated CTAB concentration $(1.0 \times$ $\left.10^{-3} \mathrm{M}-1.0 \times 10^{-1} \mathrm{M}\right)$. The same behavior of viscosity decrease was also observed by Isci et al. [12] when they investigated the influence of the cationic surfactant dodecyltrimethylammonium bromide (DTABr) on the rheological properties of a soda activated bentonite. This behavior was attributed to the formations of second layers onto the clay particles with positive excess charges, which 
created dense aggregates and settled to sediment. The initial increase in the viscosity of bentonite-CTAB system was not observed in the current study because it takes place usually at very low concentration, which was not tested in this study.

Tunc et al. [32] found that the addition of cationic surfactant tetradcytrimethyl ammonium bromide (TDTMABr) into bentonite suspension had no influence on its rheological behavior. On the other hand, they [32] found that the addition of the same surfactant to sepiolite particles led at low concentration $\left(1.0 \times 10^{-4} \mathrm{M}\right)$ to small increase in the viscosity. Further addition of surfactant resulted in a clear decrease in the clay viscosity.

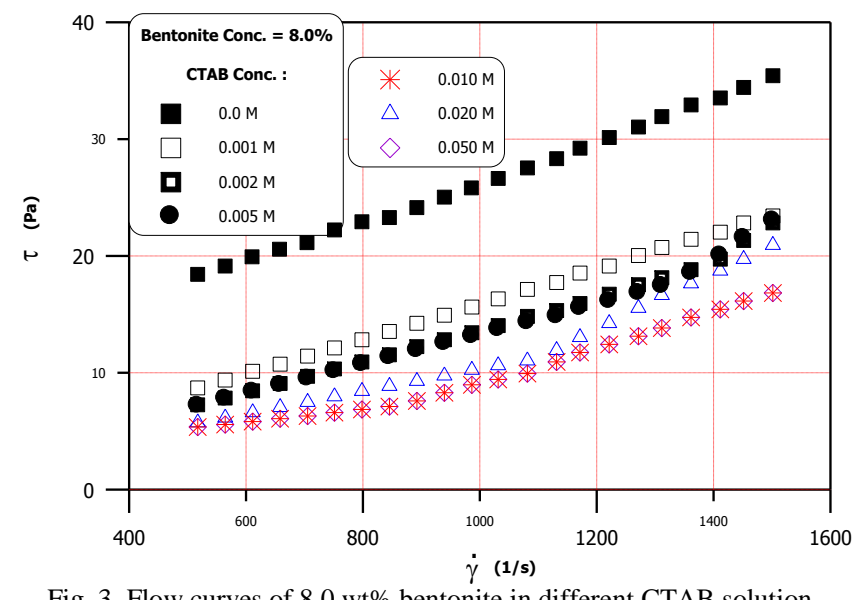

Fig. 3. Flow curves of $8.0 \mathrm{wt} \%$ bentonite in different CTAB solution concentrations.

Modeling analysis was carried out to -fit the flow behavior of the bentonite-surfactant rheological behavior using Herschel-Bulkley model (Eq. (1)). The modeling analysis parameters are reported in Table I. The yield stress value diminished after initial addition of SDS surfactant to $8.0 \mathrm{wt} \%$ bentonite dispersions, which then increased suddenly to show a maximum at $2.0 \times 10^{-2} \mathrm{M}$ of SDS. This behavior is in agreement with the behavior of the apparent viscosity. In addition, the flow behavior of $8.0 \mathrm{wt} \%$ bentonite dispersion transformed from shear thinning behavior with a yield stress to Bingham behavior in the presence of SDS surfactant; compare $n$ values in Table I. On the other hand, adding CTAB surfactant to $8.0 \mathrm{wt} \%$ bentonite dispersions removed the yield stress and transformed the behavior from shear thinning with a yield stress to Newtonian behavior, which means that the interactions between the bentonite particles was reduced to the minimum. These results are in good agreement with the behavior of the apparent viscosity discussed earlier.

The determination and analysis of the thixotropic behavior of bentonite-surfactant dispersions is the second aspect of interest in this section. The thixotropic behavior was more pronounced in bentonite-SDS dispersions than that in bentonite-CTAB dispersions. The areas of hysteresis loops reported in Table I for both surfactants are in good agreement with the behavior of the apparent viscosity. The $8.0 \mathrm{wt} \%$ bentonite showed clear thixotropic properties in SDS surfactant. The presence of hysteresis loops (i.e.: the area between the forward and backward measurements) is an indication of the shearing effect on the molecular structure of the surfactant-bentonite structure. In other words, there is an irreversible, shear-induction damaging the molecular structure of the surfactant-bentonite. As can be seen in Table I, the maximum degree of thixotropy was observed at $2.0 \times 10^{-2} \mathrm{M}$ SDS concentration, which was comparable with the degree of thixotropy of pure bentonite dispersion. For $8.0 \mathrm{wt} \%$ bentonite in CTAB solution, the area of hysteresis loops decreased with $\mathrm{CTAB}$ concentration to reach a very small value at high $\mathrm{CTAB}$ concentration. In absolute value, most of the measured areas of hysteresis loops in the case of CTAB surfactant were very small and within the error range of the experiment. It is clear that the Newtonian behavior detected for most of the $8.0 \mathrm{wt} \%$ bentonite-CTAB dispersions should be accompanied by a time-independent behavior.

The zeta potential can be considered a key indicator of the stability of bentonite dispersions. The magnitude of the zeta potential indicates the degree of electrostatic repulsion between adjacent, similarly charged particles in dispersion. Zeta potential values for bentonite-surfactant suspensions are plotted in Fig. 4. As can be seen, zeta potential values increased in absolute value with increasing the concentration of SDS surfactant. The pure bentonite suspension has -7.4 $\mathrm{mV}$ zeta potential value, but the same suspension becomes more stable after addition of $2.0 \times 10^{-2} \mathrm{M}$ SDS surfactant. This behavior of zeta potential was accompanied with general decrease in the viscosity of the suspension comparing with pure bentonite. In addition, a change in the rheological behavior of suspension from shear thinning with a yield stress for pure bentonite to Bingham material in the presence of SDS indicates that the system becomes less flocculated. Modifying the bentonite with $2.0 \times 10^{-2}$ M SDS raised the zeta potential up to $-36 \mathrm{mV}$, which can cause in an enhancement of sorption ability of metal cations [33].

On the other hand, adding the CTAB surfactant to the bentonite suspension led to decrease the absolute value of the zeta potential, indicating that the system becomes more flocculated. This result does not correlate with the trend of viscosity values after the addition of CTAB surfactant, where a clear decrease in the suspension viscosity was observed accompanied with clear change in the rheological behavior from non-Newtonian to Newtonian. It is expected that the sedimentation of the formed flocculated particles in the presence of the CTAB surfactant due to the formations of second layers onto the clay particles with positive excess charges, led to decrease the viscosity of the system [12]. Tunc et al. [32] indicted that clay particles having the zeta potential values higher than $+30 \mathrm{mV}$ or lower than $-30 \mathrm{mV}$, are considered as stable suspensions. This is the case of SDS system in this study. When the clay particles in suspension are of large negative or positive zeta potential values, they will tend to repel each other and there will be no tendency for the particles to come together. In the opposite case, like the case of CTAB, where the zeta potential values are close to zero for most of the concentrations used, particles can form aggregates in the suspension.

\section{CONCLUSIONS}

Generally, adding the SDS surfactant to the bentonite suspension led to decrease the viscosity. However, adding the SDS surfactant in the concentration range of 
$1.0 \times 10^{-2}-2.0 \times 10^{-2} \mathrm{M}$ to the bentonite dispersions resulted in some increase in the dispersion viscosity and in the degree of thixotropy. The limits of this concentration range correspond to the CMC and CCC values of SDS surfactant, respectively. In addition, the SDS surfactant modified the rheological behavior of bentonite suspension from shear thinning with a yield stress to Bingham plastic. The zeta potential values show that SDS-bentonite dispersions are stable in the SDS concentration range of $1.0 \times 10^{-2}$ to $1.0 \times 10^{-1} \mathrm{M}$. One the other hand, the addition of the cationic surfactant $\mathrm{CTAB}$ in the concentration range of $1.0 \times 10^{-3}-1.0 \times 10^{-1} \mathrm{M}$ to bentonite dispersion led to decrease the dispersion viscosity and to eliminate the yield stress and the thixotropic behavior. Moreover, the bentonite-CTAB dispersions exhibited a Newtonian behavior in the most of the investigated CTAB concentration. The reduction in both viscosity and zeta potential upon the addition of $\mathrm{CTAB}$ to the bentonite dispersions can be attributed to the formations of second layers onto the clay particles with positive excess charges, which created dense aggregates and settled to sediment.

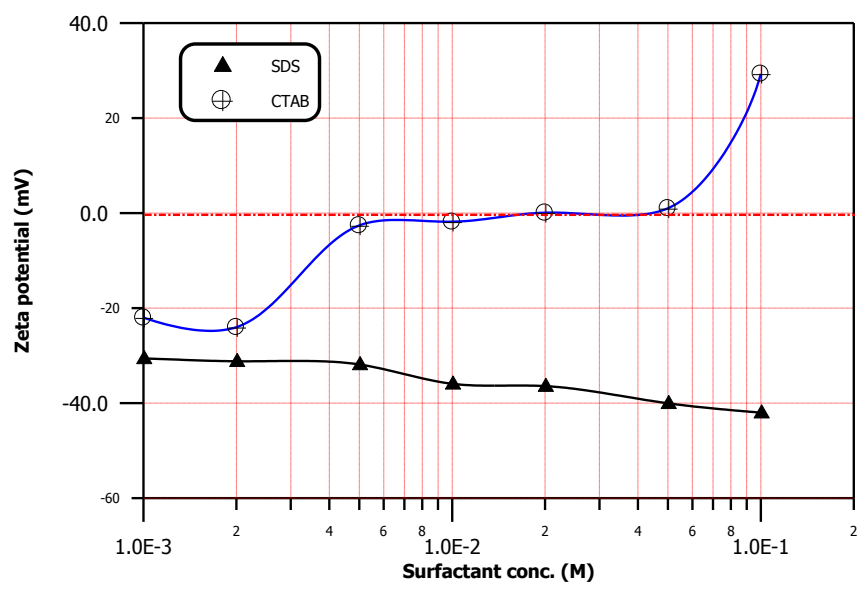

Fig. 4. Zeta potential value of bentonite dispersions at concentrations of SDS and $\mathrm{CTAB}$.

\section{ACKNOWLEDGMENT}

This work was financially supported by the Research Affairs at the UAE University under a contract no. 02-02-7-11/08. Special thanks are due to Mr. Hassan Kamal for his help in the experimental work.

\section{REFERENCES}

[1] M. I. Abdou and H. E. Ahmed, "Effect of particle size of bentonite on rheological behavior of the drilling mud," Petroleum Science and Technology, vol. 29, pp. 2220-2233, 2011.

[2] M. G. Temraza and I. Hassaniena "Evaluation of some egyptian shales as a drilling fluid additive," Energy Sources, Part A: Recovery, Utilization, and Environmental Effects, vol. 34, pp. 549-558, 2012.

[3] A. Abdel-Motelib, Z. A. Kader, Y. A. Ragab, and M. Mosalamy, "Suitability of a miocene bentonite from north western desert of egypt for pharmaceutical use," Applied Clay Science, vol. 52, no. 1, pp. 140-144, 2011

[4] A. Kaci, M. Chaouche, and P. A. Andréani, "Influence of bentonite clay on the rheological behaviour of fresh mortars," Cement and Concrete Research, vol. 41, no. 4, pp. 373-379, 2011.

[5] S. Meshram, R. Limaye, S. Ghodke, S. Nigam, S. Sonawane, and R. Chikate, "Continuous flow photocatalytic reactor using $\mathrm{ZnO}$-bentonite nanocomposite for degradation of phenol," Chemical Engineering Journal, vol. 172, pp.1008-1015, 2011.

[6] R. J. Kalbasia, A. R. Massaha, and B. Daneshvarnejad, "Preparation and characterization of bentonite/PS-SO3H nanocomposites as an efficient acid catalyst for the Biginelli reaction," Applied Clay Science, vol. 55, pp. 1-9, 2012.

[7] B. Abu-Jdayil, K. Al-Malah, and R. Sawlaha, "Study on bentonite-unsaturated polyester composite Materials," J. of Reinforced Plastics and Composites, vol. 21, pp. 1597-1607, 2002.

[8] K. Al-Malah and B. Abu-Jdayil, "Clay-based heat insulator composites: Thermal and water retention properties," Applied Clay Science, vol. 37, pp. 90-96, 2007.

[9] U. Soy, A. Demir, and F. Caliskan, "Effect of bentonite addition on fabrication of reticulated porous $\mathrm{SiC}$ ceramics for liquid metal infiltration," Ceramics International, vol. 37, pp. 15-19, 2011.

[10] Q. Wang, X. Chang, D. Li, Z. Hu, R. Li, and Q. He, "Adsorption of chromium(III), mercury(II) and lead(II) ions onto 4-aminoantipyrine immobilized bentonite," Journal of Hazardous Materials, vol. 186, pp. 1076-1081, 2011.

[11] L. Zhu and J. Ma, "Simultaneous removal of acid dye and cationic surfactant from water by bentonite in one-step process," Chemical Engineering Journal, vol. 139, pp. 503-509, 2008.

[12] S. İşçi, E. Günister, A. Alemdar, O. I. Ece, and N. Güngör, "The influence of DTABr surfactant on the electrokinetic and rheological properties of soda-activated bentonite dispersions," Materials Letters, vol. 62 , pp. 81-84, 2008

[13] J. Guo, S. Chen, and L. Liun et al., "Adsorption of dye from wastewater using chitosan-CTAB modified bentonites," Journal of Colloid and Interface Science, vol. 382, pp. 61-66, 2012.

[14] B. Gherardi, A. Tahani, P. Levitz, and F. Bergaya, "Sol/gel phase diagrams of industrial organo-bentones in organic media," Applied Clay Science, vol. 11, pp. 163-170, 1996.

[15] S. Al-Asheh, F. Banat, and L. Abu-Aitah, "Adsorption of phenol using different types of activated bentonites," Separation and Purification Technology, vol. 33, pp. 1-10, 2003.

[16] A. Gürses, S. Karaca, F. Aksakal, and M. Açikyildiz, "Monomer and micellar adsorptions of CTAB onto the clay/water interface," Desalination, vol. 264, pp. 165-172, 2010.

[17] F. Banat, S. Al-Asheh, and L. Abu-Aitah, "Examination of the effectiveness of physical and chemical activation of natural bentonite for the removal of heavy metal ions from aqueous solutions," Adsorption Science and Technology, vol. 20, pp. 151-167, 2002.

[18] S. Pura and G. Atun, "Enhancement of nitrophenol adsorption in the presence of anionic surfactant and the effect of the substituent position," Colloids and Surfaces A: Physicochem. Eng. Aspects, vol. 253, pp. 137-144, 2005.

[19] A. S. Ramamurthy, "Surfactant-enhanced removal of $\mathrm{Cu}$ (II) and $\mathrm{Zn}$ (II) from a contaminated sandy soil," Water, Air, and Soil Pollution, vol. 190, pp. 197-207, 2008.

[20] E. Günister, S. Isçi, N. Öztekin, F. Bedia Erim, Ö. Isık Ece, and N. Güngör, "Effect of cationic surfactant adsorption on the rheological and surface properties of bentonite dispersions," Journal of Colloid and Interface Science, vol. 303, pp. 137-141, 2006

[21] N. Gu"ngo"r, A. Alemdar, O. Atici, and I. O. Ece, "The effect of SDS surfactant on the flow and zeta potential of bentonite suspensions," Materials Letters, vol. 51, pp. 250-254, 2001.

[22] T. Yalcin, A. Alemdar, O. I. Ece, and N. Gu“ngo“r, "The viscosity and zeta potential of bentonite dispersions in presence of anionic surfactants," Materials Letters, vol. 57, pp. 420-424, 2002.

[23] E. Günister, S. İşçi, A. Alemdar, and N. Güngör, "Effect of sodium dodecyl sulfate on flow and electrokinetic properties of Na-activated bentonite dispersions," Bulletin of Materials Science, vol. 27, pp. 317-322, 2004.

[24] B. Abu-Jdayil, "Rheology of sodium and calcium bentonite-water dispersions: Effect of electrolytes and aging time," International Journal of Mineral Processing, vol. 98, pp. 208-213, 2011.

[25] B. Abu-Jdayil and M. Ghannam, "The modification of rheological properties of sodium bentonite-water dispersions with low viscosity CMC polymer effect," Energy Sources, Part A: Recovery, Utilization, and Environmental Effects, vol. 36, pp. 1037-1048, 2014.

[26] P. F. Luckham and S. Rossi, "The colloidal and rheological properties of bentonite suspensions," Advances in Colloid and Interface Science, vol. 82, pp. 43-92, 1999.

[27] N. Yildiz, Y. Sarikaya, and A. Calimli, "The effect of the electrolyte concentration and $\mathrm{pH}$ on the rheological properties of the original and $\mathrm{Na}_{2} \mathrm{CO}_{3}$ - activated Kutahya bentonite," Applied Clay Science, vol. 14, pp. 319-327, 1999.

[28] S. Tunc and O. Duman, "The effect of different molecular weight of poly(ethylene glycol) on the electrokinetic and rheological properties of Na-bentonite suspensions," Colloids and Surfaces A: Physicochem. Eng. Aspects, vol. 317, pp. 93-99, 2008.

[29] H. Hoffmann, A. Rauscher, M. Gradzielski, and S. F. Schulz, "Influence of ionic surfactants on the viscoelastic properties of 
zwitterionic surfactant solutions," Langmuir, vol. 8, pp. 2140-2151, 1992.

[30] V. Croce and T. Cosgrove, "Rheology, cryogenic transmission electron spectroscopy and small-angle neutron scattering of highly viscoelastic wormlike micellar solutions," Langmuir, vol. 19, pp. 8536-8541, 2003.

[31] A. M. Khan and S. S. Shah, "Determination of critical micelle concentration (CMC) of sodium dodecyl sulfate (SDS) and the effect of low concentration of pyrene on its CMC using ORIGIN software," $J$. of the Chemical Society of Pakistan, vol. 30, pp. 186-191, 2008.

[32] S. Tunc, O. Duman, and B. Kanc1, "Rheological measurements of Na-bentonite and sepiolite particles in the presence of tetradecyltrimethylammonium bromide, sodium tetradecyl sulfonate and Brij 30 surfactants," Colloids and Surfaces A: Physicochem. Eng. Aspects, vol. 398, pp. 37-47, 2012.

[33] S. H. Lin and R. H. Juang, "Heavy metal removal from water by sorption using surfactant-modified montmorillonite," Journal of Hazardous Materials, vol. B92, pp. 315-326, 2002.

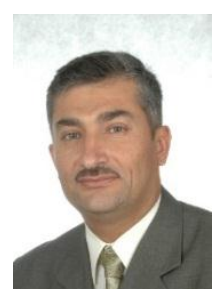

Basim Abu-Jdayil is a professor of chemica engineering in the Chemical \& Petroleum Engineering Department, UAE University. He earned his Ph.D. in fluid mechanics from the University of Erlangen-Nuermberg (Germany) in 1996. Abu-Jdayil's research specialization is in the area of rheology and composite materials. His research has resulted in more than 65 journal papers, and a lot of presentations in local and international conferences. Prof. Abu-Jdayi has supervised many plant design projects and several M.Sc's. Dr. Abu-Jdayil has worked as a consultant for AURAK (UAE), Mubadala (UAE), ROC Engineering (UAE), Ammon Co. for Dead Sea Products
(Jordan), and Intermediate Petrochemicals Co. (Jordan). Prof. Abu-Jdayil conducted many short courses in the training centers of SABIC, GASCO, Emirates Steel Industries, and TAKREER.

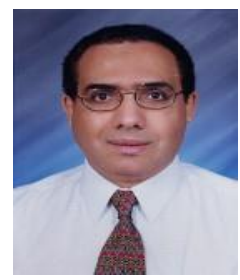

Mamdouh Ghannam is a professor of chemical engineering in the Chemical \& Petroleum Engineering Department, UAE University. He earned his Ph.D. in chemical engineering from the University of Saskatchewan (Canda) in 1991. He is a very active researcher working within several attractive fields of engineering applications such as coating and wetting behaviour of Newtonian \& non-Newtonian solutions on different solid substrate geometry, flow behaviour of crude oil-Alcoflood polymer emulsions, rheological characterisation of coating colour and polymer solutions, an interfacial properties of crude oil-aqueous solutions of different materials. He continues to publish extensively in these areas, presenting the research in international refereed journals and conferences.

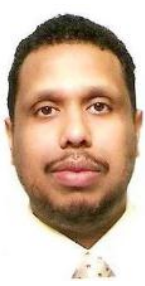

Mustafa Nasser is an assistant professor at Gas Processing Center (GPC), Qatar University. Before joining Qatar University, Dr. Nasser worked as an assistant professor at King Fahd University of Petroleum and Minerals (KFUPM) from 2012 to 2014 University of Nizwa, Sultanate Oman from 2009 to 2012. Dr. Nasser got his PhD in chemical engineering from University of Manchester, Manchester, UK in 2007. In addition, Dr. Nasser earned his MSc from University of Twente, Enschede, The Netherlands, and his BSc form Jordan University of Science and Technology (J.U.S.T), Irbid, Jordan. His research areas are categorized in the following main areas: Rheology of Complex fluids, Colloidal and interfacial phenomena, and Waste water treatment. 